\title{
Carbon Dioxide Therapy in the Treatment of Cellulite: An Audit of Clinical Practice
}

\author{
Georgia S. K. Lee
}

Received: 20 July 2008/Accepted: 17 October 2008/Published online: 29 January 2010

(C) The Author(s) 2010. This article is published with open access at Springerlink.com

\begin{abstract}
Background The clinical practice of using carbon dioxide therapy for localized adiposities was audited over a 4-year period.

Methods Patients receiving physical, dietary, or drug concurrent therapy were excluded from the audit. Original measurements in terms of mean \pm standard error of the mean (SEM) were compared with those obtained after five sessions.

Results This series included 101 women who underwent abdominal therapy. Significant reduction $(p<0.05)$ in mean upper, mid, and lower abdomen circumference was experienced by all three age groups: respectively, $1.8 \pm 0.5,1.6 \pm 0.4$, and $2.1 \pm 0.3 \mathrm{~cm}$ in the 20 - to 29 year- old group, $1.6 \pm 0.4,2.3 \pm 0.3$, and $2.1 \pm 0.3 \mathrm{~cm}$ in the 30- to 39-year-old group, and $2.0 \pm 0.4,2.5 \pm 0.4$, and $2.6 \pm 0.4 \mathrm{~cm}$ in the 40 - to 50 -year-old group. For 57 women who underwent localized thigh therapy ( 27 in the 20 - to 29-year-old group, 18 in the 30 - to 39 -year-old group, and 12 in the 40- to 50-year-old group), thigh circumference was significantly reduced in the right versus left thigh: respectively, $1.6 \pm 0.3$ versus $1.5 \pm 0.2 \mathrm{~cm}$, $1.1 \pm 0.3$ versus $1.1 \pm 0.3 \mathrm{~cm}, 1.6 \pm 0.3$ versus $1.5 \pm$ 0.4 . Weight loss was significant for older women who underwent abdominal therapy: $1.3 \pm 0.2 \mathrm{~kg}$ in the 30 - to 39 -year-old group $(n=43)$ and $1.3 \pm 0.2 \mathrm{~kg}$ in the 40- to 50 year-old group $(n=29)$. Older women who underwent thigh therapy also recorded significant weight reduction: $0.9 \pm 0.4 \mathrm{~kg}$ in the 30- to 39-year-old group $(n=18)$ and
\end{abstract}

G. S. K. Lee $(\bowtie)$

TLC Medical Practice Pte Ltd, Holland Village,

Singapore, Singapore

e-mail: enquiries@tlclifestyle.com
$1.6 \pm 0.3 \mathrm{~kg}$ in the 40 - to 50 -year-old group $(n=12)$. The results for 10 men were not significant.

Conclusion These results agree with those reported originally and demonstrate that carboxytherapy is safe and effective.

Keywords Audit - Carbon dioxide · Cellulite . Localized adiposity

Carbon dioxide $\left(\mathrm{CO}_{2}\right)$ therapy or carboxytherapy is the transcutaneous administration of $\mathrm{CO}_{2}$ for therapeutic purposes. Since Brandi et al. [1] described the efficacy of $\mathrm{CO}_{2}$ in treating localized adiposities, showing measurable reductions in maximum circumferences of the abdomen, thigh, and knee regions, there has been a worldwide interest in the treatment $[2,3]$. In the same paper, Brandi et al. [1] provided histologic evidence for the effects of $\mathrm{CO}_{2}$ gas infiltration on subdermal adipose tissue. Brandi et al. [4] subsequently reported improved skin elasticity when carboxytherapy was performed for skin irregularity after liposuction.

In this report we describe an audit of the results after carboxytherapy for the treatment of cellulite over a 4-year period (March 2004-2008) in our clinic.

\section{Patients and Methods}

Patients

The inclusion criteria for the study specified patients undergoing a minimum of five carboxytherapy sessions at 1- to 2-week intervals who were not under special dietary restrictions, not taking diet pills, and not undergoing other 
body-contouring therapy such as endermologie [5]. Contraindications to participation in the study included phlebitis; significant cardiac, respiratory, renal, or hepatic impairment; uncontrolled hypertension; and pregnancy. Some patients treated for abdominal fat reduction underwent ultrasound examination to document the presence of subepidermal cellulite.

\section{Methods}

Carbon dioxide was infused subcutaneously into the affected areas using the Carbomed Programmable Automatic Carbon Dioxide Therapy apparatus (Carbossiterapia Italiana S.R.L, Via Zanella, MI, Italy) and 30 gauge, $0.3 \times 13$-microlance needles (Fig. 1). The depth of infusion was 10 to $13 \mathrm{~mm}$. The device, calibrated to measure the dosage in milliliters, regulated the flow rate and the infusion pressure. The infusion was administered at a velocity of 50 to $100 \mathrm{ml} / \mathrm{min}$, and the total quantity of $\mathrm{CO}_{2}$ infused was 500 to $1,000 \mathrm{ml}$ for the abdomen and 800 to $1,000 \mathrm{ml}$ for each thigh over a $20-$ to 30 -min period. The therapy was continuously monitored by qualified medical personnel.

\section{Measurements}

Weight, abdominal, and thigh circumference measurements were recorded at baseline and after each treatment session. Abdominal circumferences were recorded at the levels of the upper abdomen ( $5 \mathrm{~cm}$ above the umbilicus), the mid abdomen (at the umbilicus), and the lower abdomen ( $5 \mathrm{~cm}$ below the umbilicus). Ultrasound measurement of subcutaneous fat thickness was taken immediately below the umbilicus for all patients undergoing abdominal treatments. Maximum circumferences of both the right and

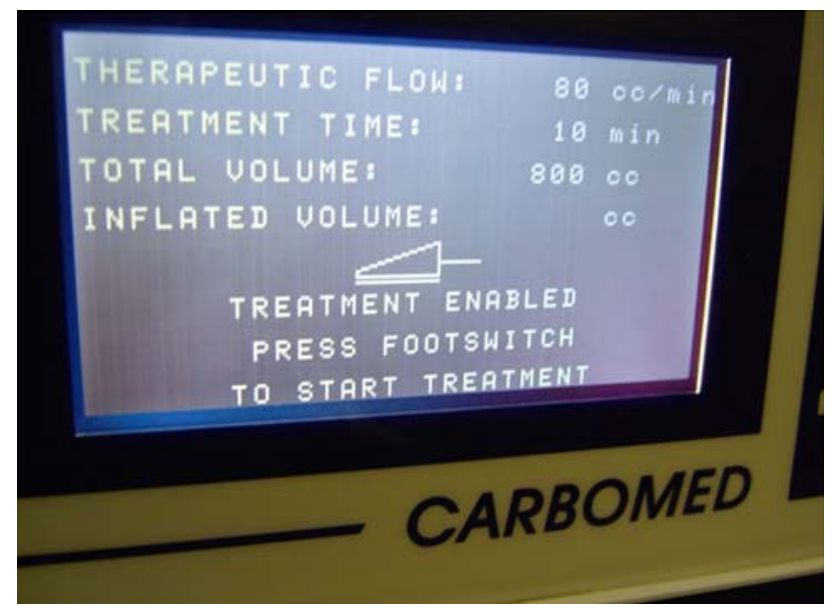

Fig. 1 Front panel of the Carbomed Programmable $\left(\mathrm{CO}_{2}\right)$ apparatus left sides of the thigh were recorded. The level of the thigh circumference measurement was recorded as the distance from the anterior superior iliac spine, and subsequent measurements were taken from the same level for each patient.

Analysis

The patients were grouped according to age (20- to 29-year-old group, 30- to 39-year-old group, and 40- to 50-year-old group), sex, and type of therapy. Measurements at baseline and 2 weeks after the fifth carbon dioxide therapy session were compared in terms of mean \pm standard error of the mean (SEM) using Student's $t$ test. Significance was set at a $p$ value less than 0.05 .

\section{Results}

A total of 101 women underwent abdominal therapy (Table 1). A significant reduction in upper, mid, and lower abdomen circumference occurred in all three age groups: respectively, $1.8 \pm 0.5,1.6 \pm 0.4$, and $2.1 \pm 0.3 \mathrm{~cm}$ in the 20 - to 29-year-old group, $1.6 \pm 0.4,2.3 \pm 0.3$, and $2.1 \pm 0.3 \mathrm{~cm}$ in the 30 - to 39 -year-old group, and $2.0 \pm 0.4,2.5 \pm 0.4$, and $2.6 \pm 0.4 \mathrm{~cm}$ in the 40 - to 50 -year-old group. For the 10 men who underwent the same therapy, the fall in abdominal circumference was not significant. For the 57 women who underwent thigh therapy (27 in the 20- to 29-year-old group, 18 in the 30- to 39year-old group, and 12 in the 40- to 50-year-old group), thigh circumference was significantly reduced respectively in the right versus left thigh $1.6 \pm 0.3$ versus $1.5 \pm$ $0.2 \mathrm{~cm}, 1.1 \pm 0.3$ versus $1.1 \pm 0.3 \mathrm{~cm}$, and $1.6 \pm 0.3$ versus $1.5 \pm 0.4 \mathrm{~cm}$.

Weight loss was significant (Table 2) for the older women who underwent abdominal therapy: $1.3 \pm 0.2 \mathrm{~kg}$ in the 30- to 39-year-old group $(n=43)$ and $1.3 \pm 0.2 \mathrm{~kg}$ in the 40- to 50-year-old group $(n=29)$. Older women who underwent thigh therapy also recorded significant weight reduction: $0.9 \pm 0.4 \mathrm{~kg}$ in the 30 - to 39 -year-old group $(n=18)$ and $1.6 \pm 0.3 \mathrm{~kg}$ in the 40- to 50-year-old group $(n=12)$. Figure 2 shows the typical ultrasound evidence of decreased subepidermal thickness after five sessions of carboxytherapy.

\section{Complications}

The complications were minor and included pain at the injection site as well as crepitus and minor aches, which did not last more than $30 \mathrm{~min}$. Some needle-entry bruising was noted, which resolved within 7 to 10 days. No other side effects were observed. 
Table 1 Change in the measurements of 101 women $(\mathrm{F})$ and 10 men $(\mathrm{M})^{\mathrm{a}, \mathrm{b}}$

\begin{tabular}{|c|c|c|c|c|c|c|}
\hline \multirow[t]{2}{*}{ Age (years) } & \multicolumn{2}{|l|}{$20-29$} & \multicolumn{2}{|l|}{$30-39$} & \multicolumn{2}{|l|}{$40-50$} \\
\hline & Before & After & Before & After & Before & After \\
\hline Upper abdomen $(\mathrm{F})^{\mathrm{c}}(\mathrm{cm})$ & $73.7 \pm 7.1$ & $71.9 \pm 6.6$ & $76.3 \pm 7.3$ & $74.7 \pm 7.2$ & $79.9 \pm 7.0$ & $78.0 \pm 9.3$ \\
\hline Mid abdomen $(\mathrm{F})^{\mathrm{c}}(\mathrm{cm})$ & $79.9 \pm 7.0$ & $78.3 \pm 6.0$ & $83.3 \pm 7.5$ & $81.0 \pm 7.5$ & $85.0 \pm 8.1$ & $82.5 \pm 7.3$ \\
\hline Lower abdomen $(\mathrm{F})^{\mathrm{c}}(\mathrm{cm})$ & $85.9 \pm 6.9$ & $83.7 \pm 6.6$ & $88.7 \pm 7.0$ & $86.6 \pm 6.5$ & $91.6 \pm 8.0$ & $89.0 \pm 8.1$ \\
\hline Upper abdomen $(\mathrm{M})^{\mathrm{d}}(\mathrm{cm})$ & $82.8 \pm 4.5$ & $79.3 \pm 3.5$ & $88.5 \pm 6.7$ & $86.2 \pm 5$ & $108.5 \pm 16.2$ & $104 \pm 15.6$ \\
\hline $\operatorname{Mid}$ abdomen $(\mathrm{M})^{\mathrm{d}}(\mathrm{cm})$ & $85.3 \pm 1.8$ & $82.5 \pm 2.1$ & $90.7 \pm 5.3$ & $88.6 \pm 4.5$ & $106.5 \pm 15.6$ & $104.5 \pm 16.3$ \\
\hline Lower abdomen $(\mathrm{M})^{\mathrm{d}}(\mathrm{cm})$ & $86.3 \pm 1.8$ & $84.0 \pm 1.4$ & $92.4 \pm 5.3$ & $89.0 \pm 3.3$ & $105.3 \pm 16$ & $103.5 \pm 16.3$ \\
\hline Right thigh $(F)^{\mathrm{e}}(\mathrm{cm})$ & $55.1 \pm 4.4$ & $53.6 \pm 4.1$ & $54.3 \pm 4.1$ & $53.2 \pm 3.9$ & $58.2 \pm 6.2$ & $56.6 \pm 5.7$ \\
\hline Left thigh $(\mathrm{F})^{\mathrm{e}}(\mathrm{cm})$ & $55.0 \pm 4.3$ & $53.6 \pm 4.0$ & $53.9 \pm 4.3$ & $52.8 \pm 3.7$ & $57.5 \pm 6.3$ & $56.0 \pm 5.8$ \\
\hline
\end{tabular}

${ }^{a}$ Values are mean \pm standard deviation

${ }^{\mathrm{b}}$ Upper abdomen (5 $\mathrm{cm}$ above umbilicus), mid abdomen (at umbilicus), lower abdomen ( $5 \mathrm{~cm}$ below umbilicus)

${ }^{c}$ Change in abdominal girth for the following female groups: 20- to 29-year-old group (29 women), 30- to 39-year old group (43 women), 40 - to 50 -year-old group ( 29 women) $(p<0.05)$

${ }^{\mathrm{d}}$ Change in abdominal girth for the following male groups: 20- to 29-year-old group (3 men), 30- to 39-year old group (5 men), 40 - to 50-yearold group ( 2 men)

e Change in thigh circumference for 57 women: 27 in the 20- to 29-year-old group, 18 in the 30- to 39-year-old group, and 12 in the 40 - to 50 -year-old group $(p<0.05)$

Table 2 Change in the weight of 101 women $(\mathrm{F})$ and 10 men $(\mathrm{M})^{\mathrm{a}}$

\begin{tabular}{|c|c|c|c|c|c|c|}
\hline \multirow[t]{2}{*}{ Age (years) } & \multicolumn{2}{|l|}{$20-29$} & \multicolumn{2}{|l|}{$30-39$} & \multicolumn{2}{|l|}{$40-50$} \\
\hline & Before & After & Before & After & Before & After \\
\hline Abdomen $(F)^{b}(k g)$ & $53.9 \pm 9.9$ & $53.0 \pm 9.5$ & $56.2 \pm 9.4^{\mathrm{c}}$ & $54.9 \pm 9.2^{\mathrm{c}}$ & $58.6 \pm 10.7^{\mathrm{c}}$ & $57.8 \pm 10.7^{\mathrm{c}}$ \\
\hline Abdomen $(\mathrm{M})^{\mathrm{d}}(\mathrm{kg})$ & $64.3 \pm 3.3$ & $64.2 \pm 3.0$ & $74.3 \pm 8.7$ & $74.3 \pm 7.9$ & $87.6 \pm 43.6$ & $87.5 \pm 40.4$ \\
\hline Thigh $(\mathrm{F})^{\mathrm{e}}(\mathrm{kg})$ & $53.7 \pm 7.6$ & $53.2 \pm 7.3$ & $51.9 \pm 8.0^{\mathrm{c}}$ & $51.0 \pm 6.9^{c}$ & $58.2 \pm 6.1^{\mathrm{c}}$ & $56.6 \pm 5.6^{\mathrm{c}}$ \\
\hline
\end{tabular}

${ }^{a}$ Values are mean \pm standard deviation

b Change in weight after abdominal therapy for the female groups: 20- to 29-year-old group (29 women), 30- to 39-year-old group (43 women), and 40 - to 50-year-old group ( 29 women)

${ }^{c} p<0.05$

${ }^{\mathrm{d}}$ Change in weight after abdominal therapy for the male groups: 20- to 29-year-old group (3 men), 30- to 39-year-old group (5 men), and 40- to 50-year-old group (2 men)

e Change in weight after thigh therapy for 57 women: 27 in the 20- to 29-year-old-group, 18 in the 30- to 39-year-old group, and 12 in the 40 - to 50-year-old group

\section{Discussion}

The women experienced a significant reduction in abdominal and thigh circumference. This was not reflected in the male group, probably because of the group was small $(n=10)$. The magnitude of the reduction $(\sim 2 \mathrm{~cm})$ was similar to that originally reported by Brandi et al. [1] in their prospective study of 48 women (all had thigh therapy and 14 also had abdominal treatment) who underwent carboxytherapy using the same equipment as in the current series. This comparison is valid because we also excluded all patients receiving concurrent drug or dietary treatment to avoid any confounding factors.

Weight loss is not the primary objective of carboxytherapy, which is aimed at treating localized adiposities and improving skin texture. However, women 30 to 50 years of age reported a small $(\sim 1 \mathrm{~kg})$ but significant weight loss after abdominal or thigh carboxytherapy. This supports the hypothesis that the site of $\mathrm{CO}_{2}$ action is restricted to localized tissue $[1,6]$.

\section{Complications}

No serious complications from carboxytherapy have been reported, as evidenced in this audit. This is hardly surprising because $\mathrm{CO}_{2}$ is widely used in medicine as the mainstay of minimally invasive surgery. During laparoscopic procedures, $\mathrm{CO}_{2}$ is routinely used inside body cavities to provide a superb view and access for the evergrowing list of surgical procedures. Hypercapnia, which 
(a)

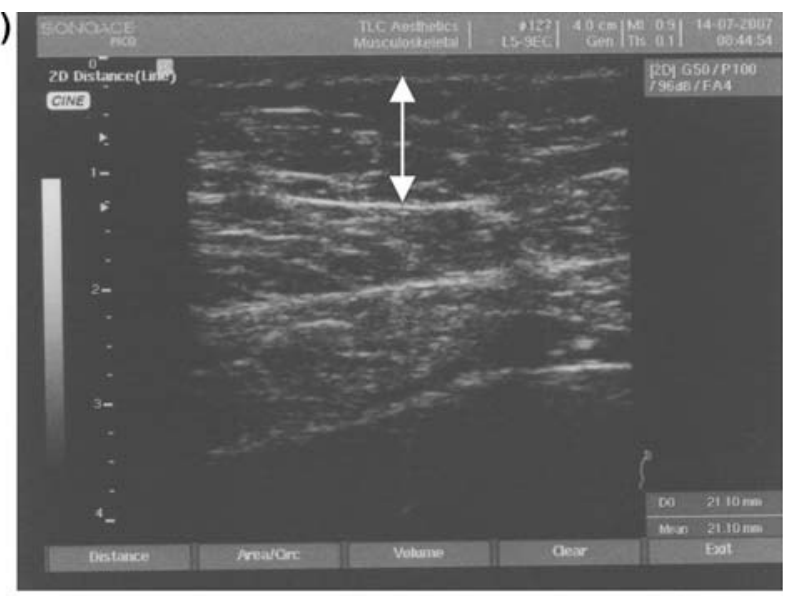

(b)

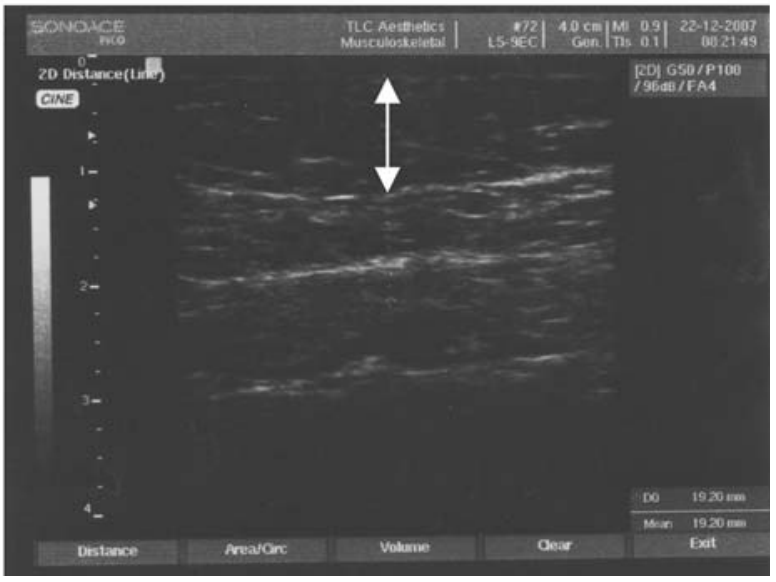

Fig. 2 Ultrasound examination of the abdomen showing measurement of subcutaneous fat before (a) and after (b) carbon dioxide $\left(\mathrm{CO}_{2}\right)$ therapy. Subepidermal thickness is reduced after carboxytherapy

incidentally does not occur during carboxytherapy [7], is very well tolerated. The equipment used in this study is manufactured in Italy and approved by the European Community (EC) for medical use.

\section{Mechanism of Action}

Sound physiologic principles underlie the possible mechanisms of $\mathrm{CO}_{2}$ action, modulating its effects on the skin and subdermal layers. In a histologic study, Brandi et al. [1] reported fracturing of the adipose tissue with release of triglycerides in the intercellular spaces and adipocytes presenting thin fracture lines in the plasma membrane. These lines did not involve the connective spaces where the major vascular structures are located. The dermis presented a thicker appearance than before the treatment, with the collagen fibers distributed more diffusely.

The same authors reported microcirculatory changes after $\mathrm{CO}_{2}$ therapy, reflected by increased perfusion as measured by laser Doppler flowmetry and increased oxygen tension as measured by transcutaneous oxygen tension. This is to be expected from the Bohr effect on the oxygen dissociation curve. Ferreira et al. [6], in a blind, interventional, crosssectional study, investigated $\mathrm{CO}_{2}$ injection in the dermis of Wistar rats. Treated rats showed intense collagen turnover in their skin samples compared with control animals, which had saline injections. These findings support the subjective clinical findings of improved skin texture after $\mathrm{CO}_{2}$ therapy.

Cellulite

Obesity is associated with decreased self-esteem and increased risk of diabetes and cardiovascular complications such as hypertension and ischemic heart disease. In a recent metaanalysis of 10 studies [8], the waist-to-height ratio, an index of abdominal obesity, was found to be a better discriminator of cardiovascular risk than body mass index (BMI). Besides liposuction, the direct therapeutic options for dealing with abdominal fat are few. Based on our results, carboxytherapy, singly or in combination, is definitely useful in this context.

\section{Subjective Benefits}

One of the main problems of applying evidence-based medicine to aesthetics is that the benefits are subjective and difficult to quantify. Carboxytherapy is no exception because the main attraction of this treatment is improvement in skin texture and elasticity [1, 2]. Brandi et al. [4] reported improved skin elasticity after carboxytherapy, as measured by the Cutometer SEM 474 Courage-Khazaka (CK Electronics, Koln, Germany) [9-11]. This finding has been confirmed by the recent development of an animal model whereby increased collagen turnover was demonstrated histologically [6].

\section{Sex and Age Differences}

Our data show the benefits of carboxytherapy to be limited for men. Although this can be explained by the lack of sufficient male patients $(n=10)$, sexual dimorphism in the subdermal connective tissue is well documented [1]. This consists of a different orientation in the sexes of the subcutaneous fibers, which extend from the dermis to the fascia, probably linked to hormonal causes [12-14]. Younger women (age, 20-29 years) appear to derive less objective benefit from carboxytherapy. This supports the view that cellulite increases with age and hence the benefits of carbon dioxide therapy are more quantifiable.

\section{Clinical Practice}

Consumer satisfaction is reflected in the widespread acceptance of carboxytherapy worldwide [2, 3]. Clearly, 
patients who enroll in wellness programs receive thorough counseling. In our practice, patients undergo basic health screening, and most patients receive concurrent dietary, lifestyle, and exercise therapies. As part of a holistic approach, $\mathrm{CO}_{2}$ and drug treatment may be added. An audit of $\mathrm{CO}_{2}$ therapy should exclude the majority of patients who enroll in a holistic program. Difficulty restricting monotherapy in clinical practice probably explains why published audits of this popular treatment are few. Conversely, it is likely that this audit may underestimate the results because physical, drug, or dietary methods are excluded.

\section{Conclusion}

The results of this audit agree with those reported in smaller prospective series, confirming that carboxytherapy is safe and effective.

Acknowledgment We are grateful to the clinic staff for their help in retrieving the data.

Open Access This article is distributed under the terms of the Creative Commons Attribution Noncommercial License which permits any noncommercial use, distribution, and reproduction in any medium, provided the original author(s) and source are credited.

\section{References}

1. Brandi C, D'Aniello C, Grimaldi L, Bosi B, Dei I, Lattarulo P, Alessandrini C (2001) Carbon dioxide therapy in the treatment of localized adiposities: clinical study and histopathological correlations. Aesth Plast Surg 25:170-174
2. Campos V, Bloch L, Cordeiro T (2007) Carboxytherapy for gynoid lipodystrophy treatment: the Brazilian experience. J Am Acad Dermatol 56:AB196

3. Koutna N (2006) Carboxytherapy: a new noninvasive method in aesthetic medicine. Cas Lek Cesk 145:841-843

4. Brandi C, D'Aniello, Grimaldi L, Caiazzo E, Stranghellini E (2004) Carbon dioxide therapy: effects on skin irregulatiry and its use as a complement to liposuction. Aesth Plast Surg 28:222-225

5. Chang P, Wiseman J, Jacoby T, Salisbury AV, Ersek RA (1998) Noninvasive mechanical body contouring: (endermologie) a oneyear clinical outcome study update. Aesth Plast Surg 22:145-153

6. Ferreira JCT, Haddad A, Tavares SAN (2008) Increase in collagen turnover induced by intradermal injection of carbon dioxide in rats. J Drugs Dermatol 7:25-30

7. Ochiai R, Takeda J, Noguchi J, Ohgami M, Ishii S (2000) Subcutaneous carbon dioxide insufflation does not cause hypercarbia during endoscopic thyroidectomy. Anesth Analg 90:760-762

8. Lee CM, Huxley RR, Wildman RP, Woodward M (2008) Indices of abdominal obesity are better discriminators of cardiovascular risk factors than BMI: a meta-analysis. J Clin Epidemiol 61:648653

9. Ballou SP, Mackiewicz A, Lysikiewicz A, Neuman MR (1990) Direct quantification of skin elasticity in systemic sclerosis. J Rheumatol 17:790-794

10. Bartell TH, Monafo WW, Mustoe TA (1988) A new instrument for serial measurements of elasticity in hypertrophic scar. J Burn Care Rehabil 9:657-660

11. Fong SS, Hung LK, Cheng JC (1997) The Cutometer and ultrasonography in the assessment of postburn hypertrophic scar: a preliminary study. Burns 23:12-18

12. Draelos ZD, Marenus KD (1997) Cellulite: etiology and purported treatment. Dermatol Surg 23:1177-1181

13. Numberger F, Muller G (1978) So-called cellulite: an invented disease. J Dermatol Surg Oncol 4:221-229

14. Rosenbaum M, Priedo V, Hellmer J, Boschmann M, Krueger J, Leibel RL, Ship AG (1998) An exploratory investigation of the morphology and biochemistry of cellulite. Plast Reconstr Surg 101:1934-1939 